\section{International Scientific Journal Theoretical \& Applied Science}

\author{
p-ISSN: 2308-4944 (print) e-ISSN: 2409-0085 (online) \\ Year: $2018 \quad$ Issue: $01 \quad$ Volume: 57 \\ Published: $30.01 .2018 \quad$ http://T-Science.org
}

I.B. Hajiyeva

Azerbaijan University of Architecture and Construction 1073, Baku, 11, A.Sultanov street, info@azmiu.edu.az Institute of Chemistry of Additives named after Academician A.M.Quliyev, ANAS 1029, Baku, Boyukshor highway, quarter 2062. irada70@yahoo.com

SECTION 9. Chemistry and chemical technology.

\title{
OBTAINING NEW XANTHOGENATE ACIDS ADDITIVES, BY MEANS OF CHLOROASETAMIDE CONDENSATION WITH FOLMALDEHYDE
}

\begin{abstract}
N$-methylolchloroacetamide, $\quad N, N^{\prime}$-oxymethylenebischloroacetamide and $\quad N, N^{\prime}$-methylene bischloroacetamide were synthesized, which has got different reactive capability and were reacted with alkaline salts of alkyl xanthogenic acids. Optimal conditions for the synthesis of $N, N^{\prime}$-oxydimethylene- and $N$, $N$ 'methylenebisalkylxanthogenatoacetamides, whose structure has been studied by IR and NMR spectroscopy methods, and are uniquely consistent with the formulas attributed to them.

Key words: chloroasetamide, xanthogenate acids

Language: Russian

Citation: Hajiyeva IB (2018) OBTAINING NEW XANTHOGENATE ACIDS ADDITIVES, BY MEANS OF CHLOROASETAMIDE CONDENSATION WITH FOLMALDEHYDE. ISJ Theoretical \& Applied Science, 01 (57): 108-110.
\end{abstract}

Soi: http://s-o-i.org/1.1/TAS-01-57-19 Doi: crostef https://dx.doi.org/10.15863/TAS.2018.01.57.19

\author{
УДК 547.484.34,547.494.254,547.233
}

\section{ПОЛУЧЕНИЯ НОВЫХ ПРОИЗВОДНЫХ КСАНТОГЕНОВЫХ КИСЛОТ, ПУТЕМ КОНДЕНСАЦИИ ХЛОРАЦЕТАМИДА С ФОРМАЛЬДЕГИДОМ}

\begin{abstract}
Аннотация: Проведена реакция взаимодействия хлор ацетамида с формальдегидом в слабощелочной среде. Синтезированы, $\quad N, N^{\prime}-\quad$ оксидиметиленбисалкилксантогенато-ацетамид $\quad$ u $-N, N^{\prime}-$ метиленбисалкилксанто-генатоацетамид, обладающие биологичес-кой активностью. Строение синтезированных соединений доказано данными ЯМР-спектроскопии.

Ключевые слова: хлорачетамид, ксантогеновые кислоты
\end{abstract}

\section{Introduction}

Проведена реакция взаимодействия хлор ацетамида с формальдегидом в слабощелочной среде. Синтезированы, $\mathrm{N}, \mathrm{N}^{\prime}-$ оксидиметиленбисалкилксантогенато-ацетамид и -N,N'-метиленбисалкилксанто-генатоацетамид, обладающие биологичес-кой активностью. Строение синтезиро-ванных соединений доказано данными ЯМР-спектроскопии.

Химическое соединение, которые имеют в молекуле серное, азотное соединение и разные функциональные группы улучшают смазывающие и биоцидные свойства присадок [15]. Поэтому, синтез новых серо- и азотосодержащих веществ имеют очень большое значение и огромный интерес в науке.
Целью настоящей работы является синтез новых соединений, содержащих наряду с ксантогеновой группой, амидную группу, установление строение и биологической активности новых потенциально биологически активных, N,N'оксидиметиленбисалкилксантогенато-ацетамида и -N,N'-метиленбисалкил-ксантогенатоацетамида.

Проведенные первичные исследования [6-7] показали, что при взаимодействии хлор ацетамида с формальдегидом получают три разных продукта:

$\mathrm{N}$-метилолхлорацетамид,-N,N'-метиленбисхлорацетамид,-N,N'-

метиленбисалкилксанто-генатоацетамид. Они являются первичными продуктами. Молекулярное строение новых продуктов, 
зависит от соотношение взятых веществ в моля, от катализатора и их характера, температуры, от продолжительности реакции.

Целью настоящей работы является синтез новых соединений, содержащих наряду с ксантогеновой группой, амидную группу, установление строений и биологической активности новых потенциально биологически активных,N,N'-

оксидиметиленбисалкилксантогенатоаце-тамида и N,N'-метиленбисалкилксанто-генатоацетамида.

\section{Materials and Methods}

Проведенные первичные исследования показали, что при взаимодействии хлор ацетамида с формальдегидом получаются три разных продукта:

$\mathrm{N}$-метилолхлорацетамид, $\quad$-N,N'-метиленбисхлорацетамид, хлорацетамид.

Они являются первичными продуктами. Молекулярное строение новых продуктов, зависит от соотношение взятых веществ в моля, от катализатора и их характера, температуры и от продолжительности реакции.

Методы исследовании показали что, чтобы получить химически чистый и высокопроцентный $\mathrm{N}$-метилолхлорацета-мид, надо создать слабую щелочную среду.

$$
\mathrm{ClCH}_{2} \mathrm{CONH}_{2}+\mathrm{CH}_{2} \mathrm{O} \stackrel{\mathrm{NaOH}}{\longrightarrow} \mathrm{ClCH}_{2} \mathrm{CONHCH}_{2} \mathrm{OH}
$$

Чистота вещества было доказано данными ЯМР-спектроскопии. Молекула Nметилолхлорацетамида содержит сигналы 3 карбоновых атомов, которые построены последовательно по нижеследующим интенсивности:

$$
\delta_{\mathrm{c}}=42.5 \text { m.h. }\left(\mathrm{CH}_{2} \mathrm{Cl}\right), 6.35 \text { m.h. }\left(\mathrm{CH}_{2}-\mathrm{O}\right) \text { və } 166.7 \text { m.h. }(\mathrm{C}=\mathrm{O}) \text {. }
$$

Более широкие исследования,в том числе зависимости от температуры, показали что при высокой температуре молекула $\mathrm{N}$ - метилолхлорацетамида конденсируя со второй молекулой, приводит к образованию N,N'оксидиметиленбисалкилксантогенатоацетамида.

$$
2 \mathrm{ClCH}_{2} \mathrm{CONHCH}_{2} \mathrm{OH} \underset{-\mathrm{H}_{2} \mathrm{O}}{\longrightarrow}\left(\mathrm{ClCH}_{2} \mathrm{CONHCH}_{2}\right)_{2} \mathrm{O}
$$

Взятый хлор ацетамид с параформ расплавляют до температуры 100-1050С и 2 часа перемешивают до получения с высоким выходом $\mathrm{N}, \mathrm{N}$-оксидиметиленбисалкилксанто-генато- ацетамида. В тоже время, проведенной при температуре 120-1300С, приводит к получении метиленбисхлорацетамида.<smiles>CNC(=O)CC1CCCC1C(=O)CCl</smiles>

\section{Conclusion}

В этом случае можно предположить что, сначала формальдегид взаимодействует с хлор ацетамидом и получается $\mathrm{N}$ метилолхлорацетамид, последний в свою очередь конденсируясь со второй молекулой хлорацетамида приводит к образованию N,N метиленбисхлорацета-мида.

Подведя итог, по полученным выводам мы получаем нижеследующую схему: 


\begin{tabular}{l|lrl|l|ll} 
& ISRA (India) & $=\mathbf{1 . 3 4 4}$ & SIS (USA) & $=\mathbf{0 . 9 1 2}$ & ICV (Poland) & $=\mathbf{6 . 6 3 0}$ \\
Impact Factor: & ISI (Dubai, UAE) $=\mathbf{0 . 8 2 9}$ & PUHU (Russia) $=\mathbf{0 . 2 0 7}$ & PIF (India) & $=\mathbf{1 . 9 4 0}$ \\
& GIF (Australia) & $\mathbf{0 . 5 6 4}$ & ESJI (KZ) & $=\mathbf{4 . 1 0 2}$ & IBI (India) & $\mathbf{4 . 2 6 0}$
\end{tabular}

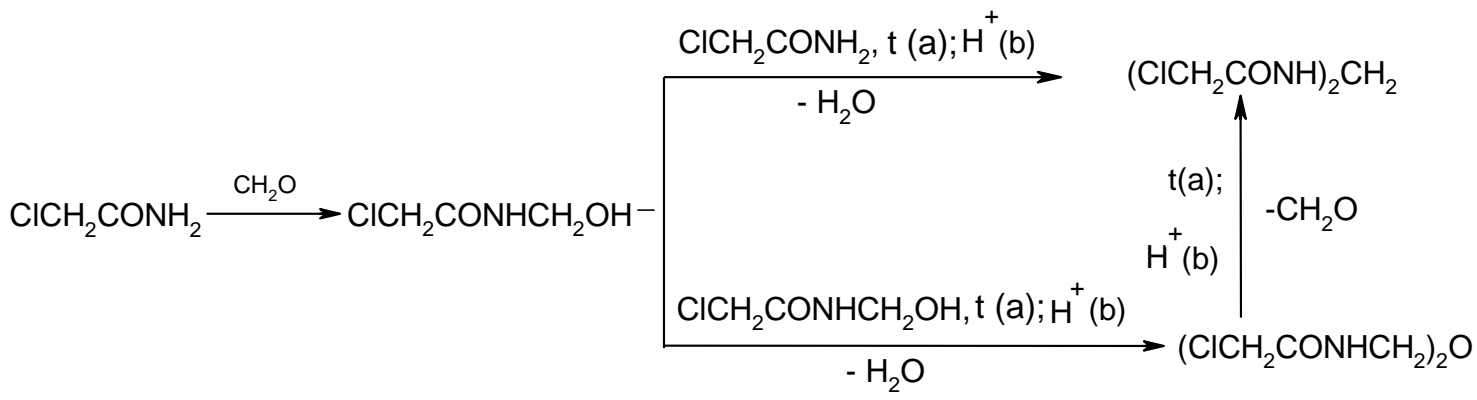

Данные -N,N'-метиленбисхлорацетамида, на ${ }^{13} \mathrm{C}$ ЯМР - спектроскопии были исследованы в растворе $\mathrm{D}_{6}$. NMR $\mathrm{H}, \delta$, m.h.: $4 \mathrm{c}\left(4 \mathrm{H}, 2 \mathrm{CH}_{2} \mathrm{Cl}\right)$, 4.44t $\left(2 \mathrm{H}, \mathrm{NCH}_{2} \mathrm{~N}\right), 8,82 \mathrm{t}(2 \mathrm{H}, 2 \mathrm{NH})$. NMR13C, $\delta$, m.h.: $42.45\left(\mathrm{CH}_{2} \mathrm{Cl}\right), 44.34\left(\mathrm{NCH}_{2} \mathrm{~N}\right), 166.7(\mathrm{C}=\mathrm{O})$.

\section{References:}

1. (1964) Preparativnaya organicheskaya khimiya. Perevod s pol'skogo Shpanova V.V. i Volodinoy V.S pod red. dokt.khim.nauk Vul'fsona N.S. M.-L.: 1964, -p.396-399.

2. (1965) Obshchiy praktikum po organicheskoy khimii. Perevod s nemetskogo pod red. prof.Kosta A.N., M.: Mir, 1965, -p.393.

3. (1968) Veygand-Khil'getag. Metody eksperimenta $\mathrm{v}$ organicheskoy khimii. Perevod s nemetskogo pod red. prof.Suvorova N.N. M.: Khimiya, 1968, -p.445-446.

4. (2006) Zayavka 2415194 Velikobritaniya. MPK7 S 07 s 231/02. Sposob polucheniya amidov zhirnykh kislot. Malaysian Palm Oil Board. Hoon Seng Soi, Ahmad Salmiah, Hassan Hazimah Abu. № 0126052.7.
Zayavl.26.11.2004. Opubl. 21.12.2005. NPK S2S. Angl.; RZhKhim. 2006, №23, 19N.75P.

5. (1949) Sintezy organicheskikh preparatov. Sb. I. Perevod s angliyskogo pod red. akademika Kazanskogo B.A. M.: In. lit., 1949, p. 476.

6. I.B.Hajiyeva, et al. (2003) The Azerbaijan Republic. Patent- invention № İ 20030106, dated: 30.05.2003. Invention name: S-(Nasetilcarbamoil) metil-O- butilxanthogenat as antiwear additive for synthetic ester oil.

7. (2006) Zayavka 2415194 Velikobritaniya. MPK7 S 07 s 231/02. Sposob polucheniya amidov zhirnykh kislot. Malaysian Palm Oil Board. Hoon Seng Soi, Ahmad Salmiah, Hassan Hazimah Abu. № 0126052.7. Zayavl.26.11.2004. Opubl. 21.12.2005. NPK S2S. Angl.; RZhKhim. 2006, №23, 19N.75P. 